\title{
Modelling-based approach of analysing diversion impacts: a case study of the Brahmaputra basin
}

\author{
Pulendra Dutta* and Arup Kumar Sarma \\ Department of Civil Engineering, Indian Institute of Technology, Guwahati 781 039, India
}

\begin{abstract}
Water resources management of the transboundary Brahmaputra river basin is challenging due to limited hydro-climatic information beyond the national boundary. The present study uses soil and water assessment tool (SWAT) to evaluate the likely impact on hydrology, due to water diversion activity. Adopting several scenarios of water diversion, simulation results of the SWAT hydrological model show a significant impact on streamflow along the downstream of a hypothetical reservoir at the Indo-China border. The monthly discharge at 'Bhomoraguri' reduces up to $15.77 \%$ against only $10 \%$ withdrawal. Besides, diversion would lead to a change in sediment discharge of the Brahmaputra.
\end{abstract}

Keywords: Hydrological model, river basin, streamflow, water diversion.

UNDERSTANDING hydrological processes within a watershed boundary is essential for planning and managing water resources. However, there are challenges to acquire complete knowledge about a natural system with several interconnected seen and unseen processes. This is further escalated for a complex river network system like the Brahmaputra river basin.

The transboundary Brahmaputra river flows randomly ${ }^{1,2}$, varying from lean flow during winter to high flow during monsoon. The daily discharge at Assam, India, is as low as $2000 \mathrm{~m}^{3} / \mathrm{s}$ during the lean period, which is as high as $30,000 \mathrm{~m}^{3} / \mathrm{s}$ during the monsoon period. The Brahmaputra carries the largest amount of water and silt among all Indian rivers. It is the lifeline of people living along its bank, especially in India and Bangladesh. Although the river basin has enormous potential for hydropower generation, navigation, tourism, etc. it is probably the least exploited. According to our knowledge, there is no policy for comprehensive management of this transboundary river basin. Therefore, integration of water, energy and food (WEF) in a single platform has not been possible till date ${ }^{3}$. Exploring the Brahmaputra hydrologically and hydraulically in a comprehensive manner is the need of the hour.

\footnotetext{
*For correspondence. (e-mail: pulendutta@gmail.com)
}

Several researchers have performed case-specific studies on a specific part of the Brahmaputra basin ${ }^{4-10}$. These studies addressed the local issues only, rather than the entire basin in a comprehensive manner. However, it is improper to assess the hydrology of the mighty Brahmaputra river basin, from the findings of such casespecific studies. Aktar et al. ${ }^{11}$ conducted a study on the entire stretch; however, they too failed to assess the hydrology of the whole basin. They calibrated and validated a hydrological model for estimating flow values at a single location (within Bangladesh) only. In the present study we have developed a hydrologic model for the entire basin adopting multi-outlet calibration/validation techniques.

A major challenge in developing a watershed model lies in obtaining correct input information. Being transboundary, it is extremely challenging to establish a hydrologic model for this river basin because of limited hydro-climatic information beyond the national boundary. The basin has a poor gauge network, especially over India. The data scarcity spatially and temporarily has wide influences on the hydrologic model results ${ }^{12-15}$. As such, the Brahmaputra poses a huge challenge to researchers, due to severe data scarcity coupled with its complex basin characteristics. This complexity is further augmented due to certain man-made activities disturbing the natural course.

Managing water resources for a transboundary river could only be possible if there exists an inter-governmental understanding among the basin-sharing co-nations ${ }^{16}$. The Brahmaputra basin is shared by four countries: China, India, Bhutan and Bangladesh. The availability status of water resources from the Yarlung-Tsangpo/Brahmaputra should be provided to the others beyond national boundaries. However, we are unaware about any mutual understanding among these riparian countries, regarding the exchange of basin data. In the absence of such understanding, hydrologic models help derive information across and beyond the boundary. As such, the present modelling approach is expected to provide science-based elements required for adopting water resources management practices of the Brahmaputra basin.

Dams and reservoirs are some man-made structures that greatly impact basin hydrology, and the upstream 
area gets transformed from a free-flowing river ecosystem to an artificial slack-water reservoir habitat. Along the downstream side, they cause serious impact on water availability, floods and the environment. Water diversion projects may lead to significant changes in downstream flows $^{17-19}$. The impact of dams and reservoir can also be analysed by generating regression models for the flow regimes ${ }^{20}$. However, such analysis demands long-term and accurate data regarding water resource parameters. In the event of data scarcity, however, hydrologic models can effectively be used to estimate the impacts of water projects on river hydrology and the surrounding environment ${ }^{21,22}$. Hydrologic models are capable of estimating such impacts, and they facilitate incorporation of the desired scenarios, for both the present and future. Based on a hypothetical diversion scenario, the present modelling approach would provide the basis for probable impacts on the Brahmaputra basin.

Water transfer from a tributary may not sometimes produce a visible impact which, however, becomes significant when done collectively for many tributaries or the main stem. The present study evaluates changes in the Brahmaputra discharges that may likely occur due to certain man-made activities upstream. Consideration of a hypothetical reservoir at the upper riparian country (China) and subsequently its impact evaluation on the lower riparian country (India) is the prime focus of this study. Although water diversion would alter several phenomena like sediment transport, groundwater flow, water quality parameters, erosion-deposition pattern, etc. this study primarily highlights the impacts on streamflow only. The results of the study would provide a basis for water resources management of the Brahmaputra basin.

\section{Study area}

The proposed study covers the transboundary Brahmaputra river basin (Figure $1 a$ ). The Brahmaputra river originates in the Chemayungdung mountain ranges which are located nearly 60 miles away from the southeast of Mansarovar lake in the Mount Kailash range in southern Tibet at an elevation of $5300 \mathrm{~m}$ amsl. Out of $2880 \mathrm{~km}$ length, the Brahmaputra flows $1625 \mathrm{~km}$ in Tibet as the 'Tsangpo' before entering India through Arunachal Pradesh, where it is popularly known as the 'Siang' river. It flows for about $35 \mathrm{~km}$ and is joined by two major tributaries, viz. Dibang and Lohit at Kobo, Assam. From this confluence point, the river is known as the Brahmaputra. After travelling $720 \mathrm{~km}$ in Assam it enters Bangladesh (as the Jamuna), where it is joined by Surma, another major river of Bangladesh. From this point, the Brahmaputra is popularly known as the Meghna, and finally merges into the Bay of Bengal to end its journey. Expanding over four different countries this mighty river basin occupies an area of nearly 600,000 sq. $\mathrm{km}$.

\section{Data}

The present study utilizes Shuttle Radar Transmission Mission (SRTM) Digital Elevation Model (DEM) having $90 \mathrm{~m}$ spatial resolution. We used MODIS-based global data of $0.5 \mathrm{~km}$ resolution for land use, and the global soil map with $0.9 \mathrm{~km}$ resolution provided by the Food and Agriculture Organization, Rome, Italy.

The present study uses four sets of daily weather data obtained from various sources (Figure $1 c$ ). The first set is the gridded global, high-resolution climate data called Climate Forecast System Reanalysis (CFSR) provided by Texas A\&M University (TAMU), USA. These data are available for 36 years (1979-2014), and consist of six variables: precipitation ( $\mathrm{pcp}$ ), maximum/minimum temperature (max/min tmp), relative humidity (hmd), solar radiation (slr) and wind speed (wnd). Among the numerous grid points available within the basin boundary, only 35 stations are selected so that at least one station falls under each of the major sub-basins, based on its spatial extent. The second set includes Indian Meteorological Department (IMD) station data available for six stations. These data consist of four variables (pcp, $\max / \mathrm{min}$ tmp, wnd), spanning over 25 years (19912015). The third dataset includes measured weather data at eight gauge stations over Tibet (China), obtained through an academic collaboration. These data contain six variables spanning over 22 years (1991-2012) records. The fourth dataset includes the global, IMD gridded weather data generated at the Indian Institute of Technology Madras, Chennai, containing pcp and tmp ( $\min / \max )$, and is available up to the year 2005. Following the guidelines of the soil and water assessment tool (SWAT) user manual, the missing values were filled with negative 99, which means that SWAT is directed to generate them based on available records. For the present study, we obtained streamflow records from the Central Water Commission (CWC), corresponding to five locations (Figure $1 d$ ).

\section{Methods}

This study was carried out using SWAT, which simulates the physical processes through multiple input parameters like topography, land use, climate variables and soil properties $^{23}$. SWAT has been successfully applied earlier by many researchers. Some of these studies include quantitative assessment of flow and sediment $t^{15,24-27}$ and qualitative assessment of water ${ }^{12,28-31}$. Besides, it is computationally efficient and capable of continuous simulation over long periods ${ }^{32,33}$. The topographic features like elevation and slope are extracted from DEM (Figure $1 b$ ). Generating the stream network for a threshold drainage area of 20,000 sq. km, the basin boundary is delineated. As many as 41 outlets were manually added to make provision for input at better spatial variability, 


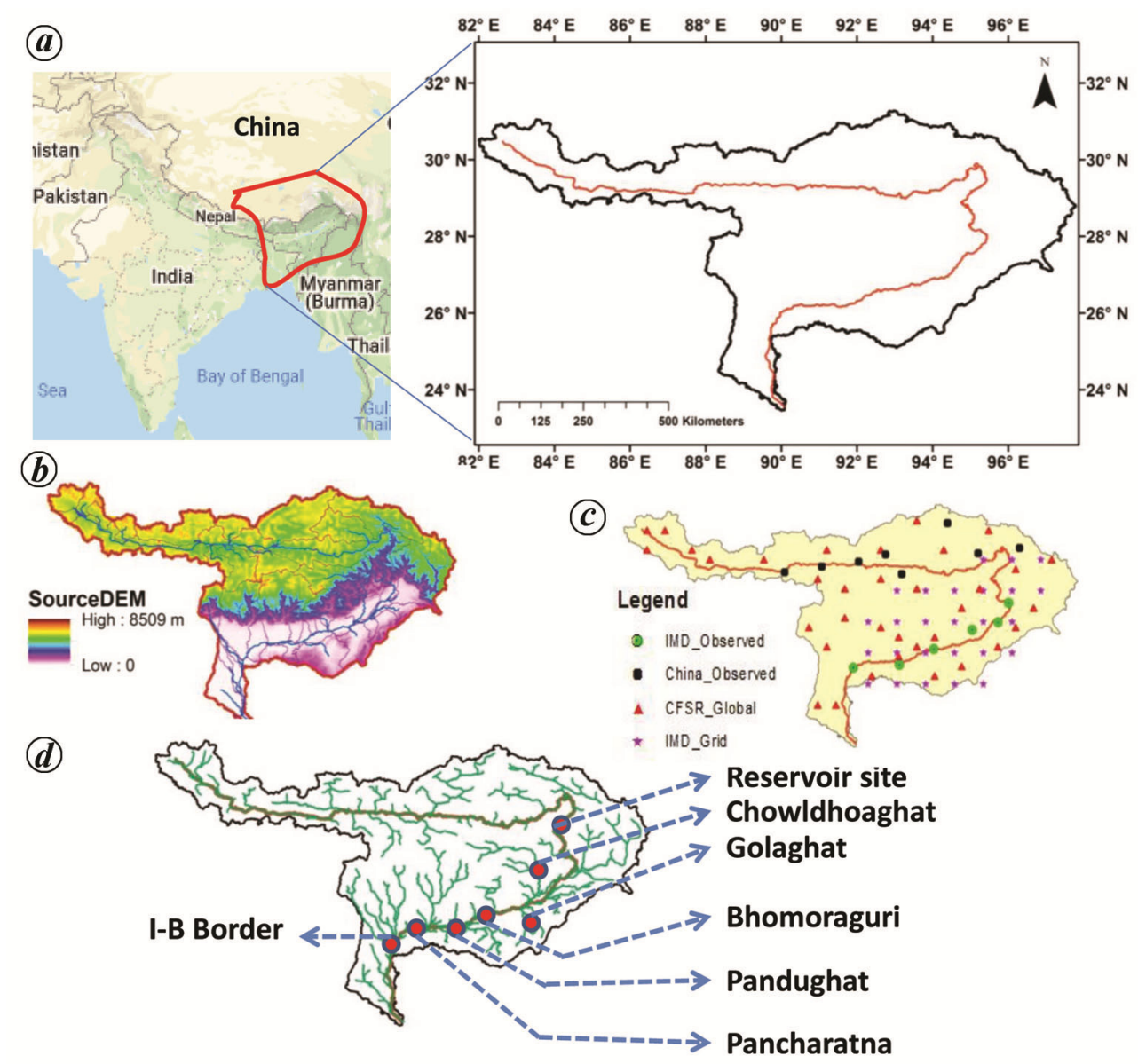

Figure 1. Brahmaputra river basin: (a) site map, (b) topographic map, (c) weather stations considered in the present study and $(\boldsymbol{d})$ stream networks and locations of stream gauges and reservoir site.

which means that the SWAT simulation requires weather datasets corresponding to at least 41 weather stations. The basin was sub-divided into several sub-basins, which were further discretized into 1578 hydrological response units (HRUs). We developed various SWAT models independently using different sets of input data, especially weather. The capability of each dataset in simulating the streamflow was evaluated to identify the best suitable dataset for the study basin. Only the model which provided satisfactory results has been presented here.

The models developed in ArcSWAT2012 were further calibrated and validated in the SWAT-CUP platform. The ArcSWAT ArcGIS extension is a graphical user interface for SWAT, which is a semi-distributed watershed simulator operating on the daily time-step ${ }^{32,34}$. SWAT-CUP comprises all sources of uncertainties related to the model parameters and data error, wherein sequential uncertainty fitting (SUFI2) algorithm is applied for model parameterization, sensitivity and uncertainty analysis. Sensitivity was determined using a multiple regression approach, which regresses Latin hypercube generated parameters against the objective function. Table 1 presents the list of sensitive parameters identified for calibrating discharges of the Brahmaputra basin. SUFI2 follows an iterative process to update the old value of the parameter with a new one. Whereas it adopts sequential fitting processes for incorporating the parameter uncertainty. Initially, the algorithm considers a large uncertainty range to ensure that the observed values lie within the 95PPU (95\% prediction uncertainty) band for the first iteration. The parameter uncertainty range is made more narrow for subsequent iterations and continued till a satisfactory result is obtained.

We had to restrict the model simulation for 15 years (1991-2005) because the fourth set of weather data was available only till 2005. The performance evaluation of the model was carried out using certain statistical parameters: (i) coefficient of determination $\left(R^{2}\right)$ which indicates a power of the relationship between the observed and simulated flow values; (ii) Nash-Sutcliffe (NS) coefficient that replicates how well the observed values fit the simulated ones; (iii) $P$-factor which shows the percentage of measured data bracketed by (95PPU) and (iv) $R$-factor that represents the thickness of 95PPU, and a measure of uncertainty.

The hydrologic model thus established was finally re-run for certain hypothetical water diversion scenarios. 
Table 1. Sensitive parameters for the present model

\begin{tabular}{lrrr}
\hline & \multicolumn{2}{c}{ Range } \\
\cline { 2 - 3 } Parameter (description) & Low & High & Best-fitted value \\
\hline r_sol_awc (average available soil water content) & 0.125 & 0.348 & 0.196 \\
r_alpha_bf (base flow recession factor; days) & 0.054 & 0.503 & 0.246 \\
r_cn2 (SCSII curve number) & -0.545 & -0.173 & -0.354 \\
a_revapmn (threshold water depth in shallow aquifer required for revap) & 0 & 127.083 & 111.516 \\
v_gw_revap (groundwater revap coefficient) & 0.110 & 0.184 & 0.135 \\
v_gw_delay (groundwater delay time; days) & 0 & 128.800 & 79.162 \\
v_smtmp (snowmelt base temperature; ${ }^{\circ}$ C) & 0.970 & 4.920 & 1.276 \\
v_gwqmn (threshold water depth in shallow aquifer required for return flow) & 1.457 & 2.753 & 1.875 \\
v_esco (soil evaporation compensation factor) & 0.828 & 0.897 & 0.888 \\
\hline
\end{tabular}

Note: r, Relative; v, replace and a, Absolute.

A water reservoir was hypothetically selected at a location just before the Brahmaputra enters India, and assuming its height as $116 \mathrm{~m}$ above the reservoir base, the parameters like surface area $(5.79 \mathrm{sq} . \mathrm{km})$ and volume $\left(291 \mathrm{Mm}^{3}\right)$ corresponding to the reservoir full condition were estimated using DEM. Water withdrawn from the reservoir is diverted beyond the basin boundary and would no longer contribute to the stream again. This reservoir at an elevation of $1896 \mathrm{~m}$ amsl is expected to significantly impact on river discharges and sediments along the downstream.

\section{Results and discussion}

\section{Spatial calibration/validation}

The SWAT model was established using all the four weather datasets in combination. The model simulation used three variables ( $\mathrm{pcp}, \max / \mathrm{min} \mathrm{tmp}$ ) that are commonly available in all the weather datasets. For a small watershed, the process of calibration at a single location is judicious because of homogeneous characteristics. However, a hydrologic model for a large watershed requires calibration considering multi-sites, to represent heterogeneous watershed characteristics. This is because single-site calibration for a large watershed might result in a combination of under/over-estimation of the values ${ }^{22}$. For a better intra-watershed spatial accuracy, we adopted the process of multi-site calibration/validation at five locations (Figure $1 d$ ). We could not utilize data pertaining to locations uniformly distributed throughout the basin, due to difficulty in obtaining them beyond the Indian boundary.

Figure 2 shows the time-series plot of calibration and validation for flows at all the five locations. Following the data secrecy policy of CWC, we have presented only the average values of the results of the SWAT model calibrated/validated on a monthly time-step basis. The lengths of discharge datasets are non-uniform, due to which the calibration periods were chosen differently.
However, the validation period (2002-05) was kept the same at all outlets. The performance of the SWAT model was evaluated based on the magnitude of statistical parameters like $R^{2}$, NS, $P$-factor and $R$-factor; the first two are shown for calibration and the other two for validation outputs. The tributary outlets (Chowldhoaghat, Golaghat) conform to inferior statistical outputs compared to those at the main-stem outlets (Figure 2).

This is due to significant differences in the observed and simulated flow values at the tributary outlets, compared to those at the main-stem outlets. Actually, flow values at the tributary outlet are relatively very low, and a small deviation in the simulated discharge leads to greater change but inferior model statistics. The model results for $R^{2}$ and NS are fair corresponding to the main-stem locations, with the respective values being 0.86 and 0.70 (Bhomoraguri), 0.91 and 0.87 (Pandughat), 0.84 and 0.74 (Pancharatna). On the contrary, these parameters at the tributary outlets are relatively inferior with values of 0.72 and 0.24 (Chowldhoaghat), and 0.68 and 0.54 (Golaghat) respectively. A similar result was also noticed for the validation statistics. According to the SWAT user manual, for acceptance a model needs to yield a $P$-factor greater than 0.7 , whereas the $R$-factor should be nearly 1.0. The high values of $P$-factor $(0.94)$ and $R$-factor (0.91) at Pancharatna indicate a fair measure of uncertainty and reflect good strength of the model. It is unfair to expect good statistics against each outlet during multisite calibration and validation of a model for a large watershed, due to its complex characteristics. However, a balance among the parameters is required for reasonably evaluating the performance of the model. As such, the SWAT model developed in this study may be considered as acceptable to represent the basin hydrology.

\section{Impact on flow along the downstream due to water diversion in the upstream}

Impact on monthly discharges: Figure 3 shows the reduction in flow values at the downstream locations of 


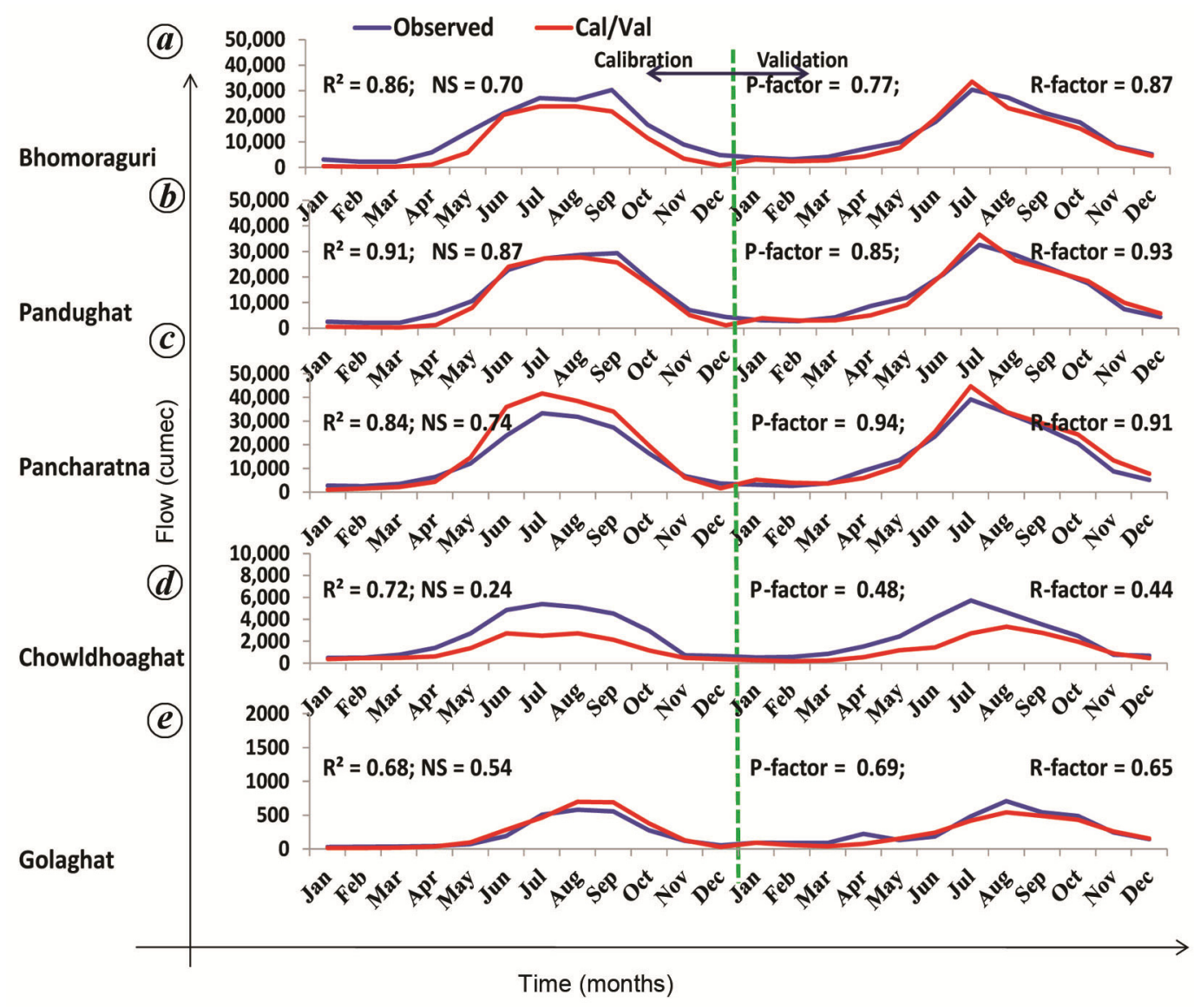

Figure 2. Spatial calibration (up to 2001) and validation (2002-05) results of the SWAT model at five locations: (a) Bhomoraguri, (b) Pandughat, (c) Pancharatna, (d) Chowldhoaghat and (e) Golaghat. These results on a monthly time step are presented as average values during the respective periods of calibration (or validation) following data sharing policies of the Central Water Commission).

the Indo-China border. This reduction is obtained from the hydrologic model (SWAT) run results for water withdrawal at the rate of $10 \%, 25 \%, 50 \%$ and $80 \%$ of the simulated discharge values at the reservoir site. Figure 3 also shows the flow values generated by the hydrologic model simulation based on a monthly time step at four downstream locations.

The flow reduction is not constant throughout the year corresponding to a particular scenario of diversion. For example, the flow at Bhomoraguri (Figure $3 a$ ) reduces in the range between $2.89 \%$ and $15.77 \%$ corresponding to the $10 \%$ diversion scenario. Here, the minimum value $(2.89 \%)$ is during February, whereas the maximum value $(15.77 \%)$ is during August month. Similarly, reduction in flow values at the same location lies in the range 3.80 $30.72 \%, 16.09-43.50 \%$ and $18.79-60.00 \%$, corresponding to $25 \%, 50 \%$ and $80 \%$ diversions respectively. It is obvious from Figure 3 that higher rates of water withdrawal from the upstream location, in general, lead to higher rates of flow reduction at all the downstream points, with little deviations during certain months. The results of the SWAT hydrologic model shows that base flow takes longer duration ( $>31$ days) to contribute to the main-stem discharge. This contribution, especially during the lean period (December-March) is significant; thus flow reduction occurs at a lower rate. However, the flow reduction during March at Bhomoraguri is quite significant $(32.24 \%$ and $51.69 \%$ ), corresponding to $50 \%$ and $80 \%$ water diversion respectively. This is due to the higher intensity of rainfall (Figure $4 a$ ) surrounding the water withdrawal site (i.e. Indo-China border). The higher amount of rainfall $(>200 \mathrm{~mm})$ produces more run-off at this site. As discussed earlier, water withdrawal depends upon the run-off at the reservoir site. Therefore, more water withdrawal from the reservoir leads to more reduction at the subsequent downstream locations.

The flow reduction in April is only $16.09 \%$ and $18.79 \%$ corresponding to $50 \%$ and $80 \%$ water withdrawal respectively. This is because the spatial variation in rainfall across the basin impacts the reduction percentage. During this month, areas starting from the immediate upstream location of the diversion site to the Bhomoraguri site experience more rainfall (101-200 mm; Figure 4b), than other areas of the basin. As such, the actual flow production by the hydrologic model at the diversion site becomes relatively low. However, flow production at 


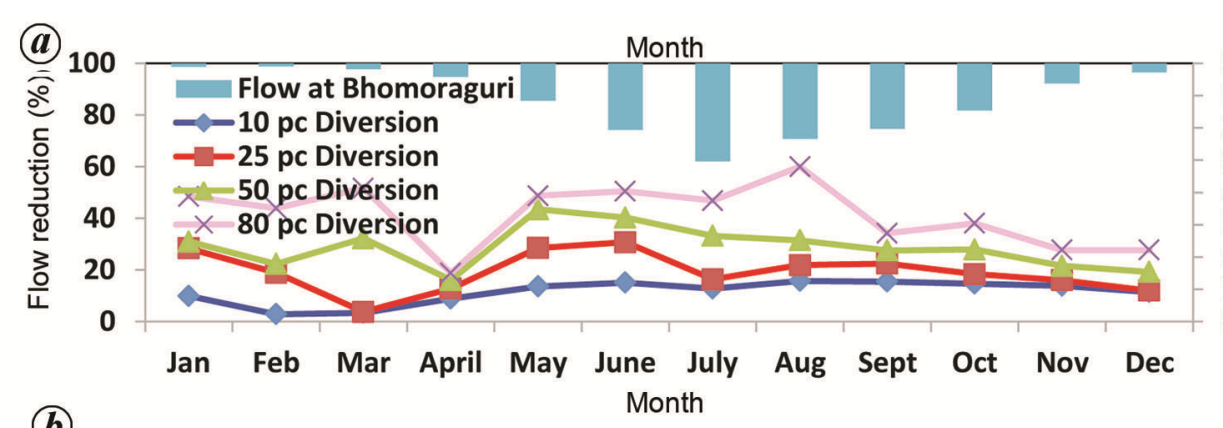
0 10,000 20,000 品 30,000 है 40,000 @ 50,000 근 60,000 70,000 은 80,000

(b)

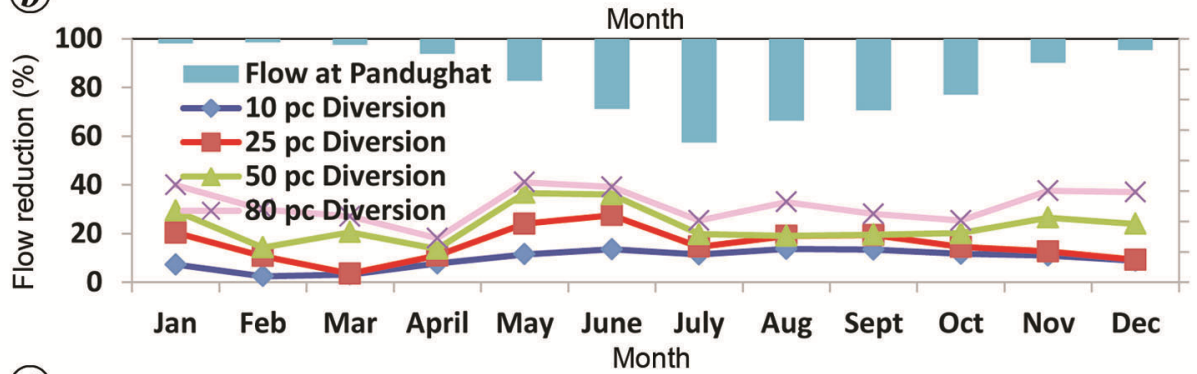
0 10,000 两 20,000 है 30,000 40,000 品 50,000 而 60,000 70,000 흔 (c) Month

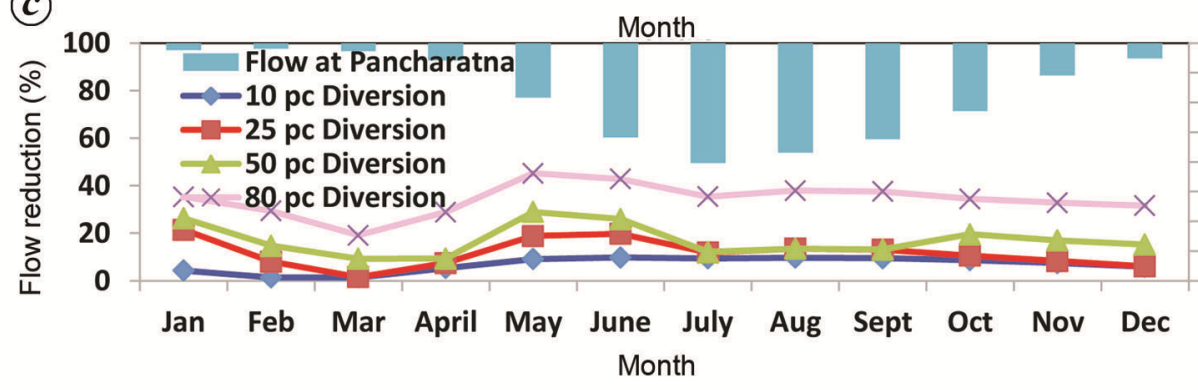
0 10,000 20,000 学 30,000 है 40,000 50,000 60,000 70,000 은 80,000 ㄴ

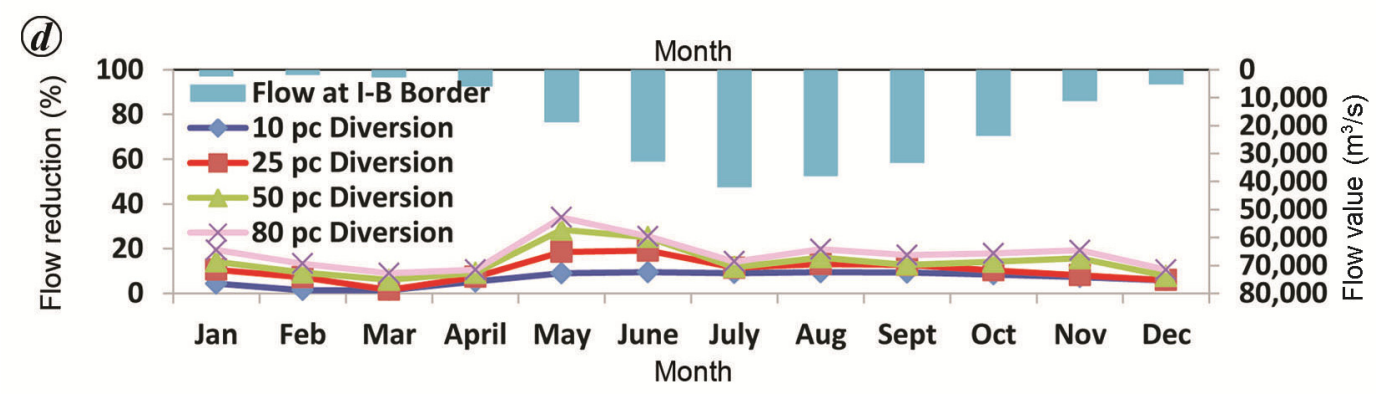

Figure 3. Reduction (\%) in monthly flow values due to flow diversions at the rate of $10 \%$ (blue), $25 \%$ (red), $50 \%$ (green) and $80 \%$ (pink) from the reservoir site at the Indo-China border. The simulated flow values are shown in the secondary vertical axis for four downstream locations: $\boldsymbol{a}$, Bhomoraguri; $\boldsymbol{b}$, Pandughat; $\boldsymbol{c}$, Pancharatna; $\boldsymbol{d}$, Indo-Bangla border.

Bhomoraguri is much higher since several tributaries join the main stem between this point (i.e. Bhomoraguri) and the diversion site, and contribute to the main stem discharge. Therefore, there is insignificant reduction in the flow values at Bhomoraguri in April, despite water withdrawal at significant rates.

The monsoon season of the Brahmaputra basin starts in late April and continues till early July (Figure $4 c$ and $d$ ) in most of the northern part of the basin which, however, starts a little late and continues up to August for other areas. As such, flow reduction is maximum during MayJune at all the downstream locations. Surprisingly, this reduction, generally decreases during July and August (Figure 3), due to higher amount of rainfall causing more water contribution from the tributaries to the main stem discharges. Moreover, the magnitude of water reduction along the downstream locations decreases, because several tributaries join the main stem and contribute to the flow. The groundwater contribution may be another factor for low values of reduction percentage along the downstream points. Among the four salient locations considered within the lower riparian country (India) for transboundary effects, 'Bhomoraguri', a point nearly $450 \mathrm{~km}$ from the diversion site is likely to experience the 

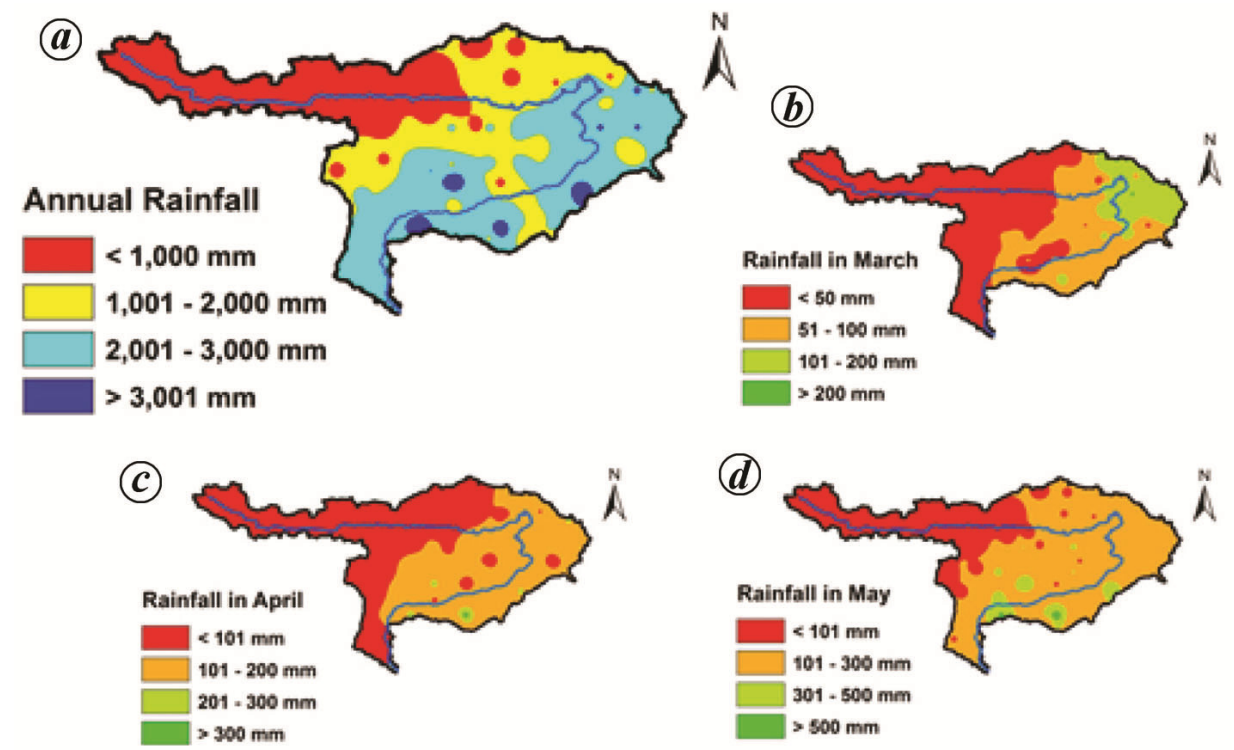

Figure 4. Total rainfall over the Brahmaputra basin during (a) Annual and (b-d) monthly (b) March, (c) April and $(\boldsymbol{d})$ May basis. Here, annual (or monthly) rainfall values at a weather station are obtained by summing up the daily rainfall values during that particular year (or month). The final values for rainfall as shown in the above plots represent the average of all such values during the entire study period (1991-2012).

highest impact. On the other hand, the Indo-Bangla border, the farthest point from the diversion site, is likely to have the least impact due to water withdrawal. Here, the maximum monthly reduction in flow values is $34 \%$ corresponding to $80 \%$ diversion. Whereas the respective values at the other locations are higher $-60 \%$ (Bhomoraguri), 42\% (Pandughat) and 43\% (Pancharatna). This is because several tributaries join the main stem between the diversion site and the Indo-Bangla border contributing to the Brahmaputra river discharges.

Impact on annual discharges: Due to the withdrawal of water from the reservoir, the downstream discharge values are likely to fall short of the normal flows. It is observed that impact of the reservoir with $10 \%$ diversion leads to a flow reductions of $12 \%$ (Bhomoraguri), $9.65 \%$ (Pandughat), 6.85\% (Pancharatna) and 6.66\% (IndoBangla border). A similar phenomenon is observed for the other rates of diversion. The immediate downstream location, i.e. Bhomoraguri is likely to experience the highest decrease in annual discharge as 12\%,19\%, 29\% and $42 \%$, resulting from $10 \%, 25 \%, 50 \%$, and $80 \%$ withdrawal respectively. Whereas the respective values are lower at the successive downstream locations. This is because several tributaries join the Brahmaputra within India. The rainfall magnitude in these tributary basins is relatively higher than the upstream locations. As such, flow production from these sub-basins significantly contributes to the river flow of the main-stem Brahmaputra. The most downstream location, i.e. the Indo-Bangla border is likely to suffer the least impact due to the diversion.
Impact on water quality along the downstream due to water diversion in the upstream: The Brahmaputra basin lacks observed data required for water resource planning and management. Therefore, hydrologic models can provide such information at fine spatial and temporal scales. The SWAT model provides several outputs like discharge, velocity, water quality parameters, sediments, etc. Such a hydrologic model calibrated for a specific variable can be applied to derive information regarding other variables present in its output database, including discharge, the calibrated parameter in the present study. Thus, the SWAT model can provide a basis for deriving information, especially during non-availability of historical records. Following the quantitative assessment, qualitative assessment of the water diversion phenomenon is addressed here with special emphasis on sediment concentration.

Figure 5 shows the alteration of sediment concentration at certain selected locations, due to water withdrawal from the Indo-China border. It shows that the impact on sediment concentration is significant only during the high flow periods (April-October). For example, the original values of total sediment transported $(\mathrm{mg} / \mathrm{l})$ at Bhomoraguri during January, June and December are 68.8, 219.8 and $99.9 \mathrm{mg} / \mathrm{l}$ respectively. However, the model run using reservoir provided the respective values as 65.9, 171.4 and $95.3 \mathrm{mg} / 1$ corresponding to $80 \%$ water withdrawal. This means that certain sediments are trapped in the reservoir, and even transported along with the water diverted. Moreover, the diversion has a small impact during the lean period (November-March). The river flow carries less amount of sediments during the lean period. 

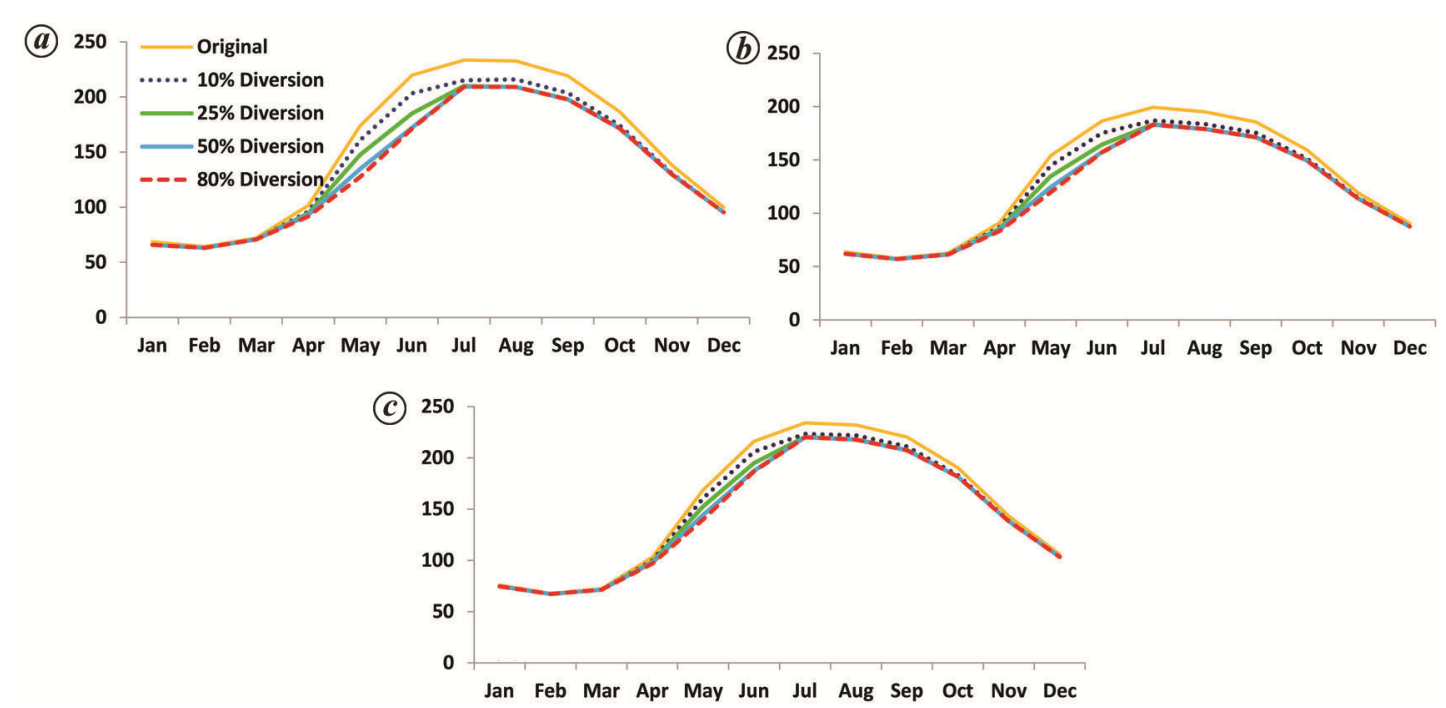

Figure 5. Changes in sediment concentration at: (a) Bhomoraguri, (b) Pandughat and (c) Pancharatna due to water diversion at the Indo-China border. Here, vertical axes represent the average values of sediment concentration (mg/l) against each month of the year.

This is because the water flowing low is incapable of producing much sediments from the watershed. On the other hand, water flowing high can erode banks, adding more sediments to the river flows.

The maximum sediment concentration at Bhomoraguri and Pancharatna was observed during July and (234 mg/1) for both the locations. Bhomoraguri is the nearest point from the reservoir site. As such, sediments would either be trapped or carried by the diverted water leading to a decrease in sediment concentration at this point. However, this decrease is not significant at Pancharatna, the farthest point considered in the analysis. This is because the alluvial characteristics of the basin between Bhomoraguri and Pancharatna lead to sediment losses at high rates. Such high values of sediment concentration affect human health and aquatic habitats, including loss of wetlands, and recreational attributes. Some other water-quality parameters like nitrogen, phosphorus, nitrates, ammonium, dissolved oxygen, etc. can be assessed by the hydrologic models, even with due consideration of manmade structures. Based on the qualitative analyses for these parameters, the processes and cost of treatment of water, if derived for water-supply projects, can be ascertained.

\section{Conclusion}

The SWAT hydrologic model provided a good mathematical representation for the Brahmaputra basin. Besides, the higher values of $R$-factor, especially at Pancharatna (0.91), indicate a good measure of uncertainty. Therefore, analysis of water diversion would warrant acceptable results showing substantial attenuation in river discharges. Annual streamflow at Bhomoraguri would reduce up to $42 \%$, if China retains $80 \%$ river water. The impact of water diversion continues far downstream, and the scale of impact would change if the diversion policy is changed. The ability of the present model to quantify transboundary effects would make it useful to stakeholders of the Brahmaputra water resources management.

\section{Conflict of interest: None.}

1. Heikman, S. K, Derry, L. A., Stedinger, J. R. and Duncan, C. C., A simple predictive tool for lower Brahmaputra River Basin monsoon flooding. Earth Interact., 2007, 11(21), 1.

2. Maheshwari, R. and Sarma, A. K., Streamflow forecasting for Brahmaputra River: a time series and neural network approach. M Tech Dissertation, Indian Institute of Technology Guwahati, 2005.

3. Wicaksono, A. and Kang, D., Nationwide simulation of water, energy, and food nexus: case study in Korea and Indonesia. J. $\mathrm{Hy}$ dro-Environ. Res., 2019, 22, 70-87.

4. Akhtar, M. P., Sharma, N. and Ojha, C. S. P., Braiding process and bank erosion in the Brahmaputra River. Int. J. Sediment. Res., 2011, 26, 431-444.

5. Apurv. T., Mehrotra, R., Sharma, A., Goyal, M. K. and Dutta, S., Impact of climate change on floods in the Brahmaputra basin using CMIP5 decadal predictions. J. Hydrol., 2015, 527, 281-291.

6. Ghosh, S. and Dutta, S., Impact of climate change on flood characteristics in Brahmaputra basin using a macro-scale distributed hydrological model. J. Earth Syst. Sci., 2012, 121(3), 637-657.

7. Gogoi, M. P., Gogoi, B., Hazarika, S. and Borgohain, P., GIS based study on fluvio-morphology of the river Brahmaputra in part of upper Assam, NE India. J. Frontline Res., 2012, 2, 114-121; ISSN: 2249-9903.

8. Goswami, D. C., Brahmaputra River, Assam, India: physiography, Basin denudation and channel aggradation. J. Water Resour. Res., 1985, 21(7), 959-978.

9. Sahoo, S. N. and Sreeja, P., Development of flood inundation maps and quantification of flood risk in an urban catchment of Brahmaputra River. ASCE-ASME J. Risk Uncertainty Eng. Syst., Part A, 2015, A4015001. 
10. Sarma, J. N., Fluvial process and morphology of the Brahmaputra River in Assam, India. J. Geomorphol., 2005, 70, 226-256; doi:10.1016/j.geomorph.2005.02.007.

11. Aktar, N. et al., Climate change impacts on water availability in the Brahmaputra basin. In Fifth International Conference on Water and Flood Management, 2015; www.researchgate.net/publication/ 281610569.

12. Chen, L. et al., Influence of rainfall data scarcity on non-point source pollution prediction: implications for physically based models. J. Hydrol., 2018, 562, 1-16.

13. Ploeg, M. J. V. D., Haldorsen, S., Leijnse, A. and Heim, M., Subpermafrost groundwater systems: dealing with virtual reality while having virtually no data. J. Hydrol., 2012, 475, 42-52; doi: 10.1016/j.jhydrol.2012.08.046.

14. Tabari, H., Kisi, O., Ezani, A. and Talaee, P. H., SVM, ANFIS regression and climate based models for reference evapotranspiration modeling using limited climatic data in a semi-arid highland environment. J. Hydrol., 2012, 444, 78-89.

15. Valdivieso, F. O. and Sendra, J. B., Semi-distributed hydrological model with scarce information: application to a large South American Binational Basin. J. Hydrol. Eng., 2014, 19(5), 1006-1014.

16. Thu, H. N. and Wehn, U., Data sharing in international transboundary contexts: the Vietnamese perspective on data sharing in the Lower Mekong Basin. J. Hydrol., 2016, 536, 351-364.

17. Biemans, H. et al., Impact of reservoirs on river discharge and irrigation water supply during the 20th century. J. Water Resour. Res., 2011, 47, W03509; doi:10.1029/2009WR008929.

18. Li, B. S., Zhou, P. J., Wang, X. Y. and Zhu, L., Opportunities and eco-environmental influence of cascade hydropower development and water diversion projects in Hanjiang River Basin. J. Geol. Soc. India, 2013, 82, 692; https://doi.org/10.1007/s12594-0130207-3.

19. Zhu, X., Zhang, C., Yin, J., Zhou, H. and Jiang, Y., Optimization of water diversion based on reservoir operating rules: analysis of the Biliu River Reservoir, China. J. Hydrol. Eng., 2014, 19(2), 411-421.

20. Talukdar, S. and Pal, S., Impact of dam on inundation regime of flood plain wetland of Punarbhaba River Basin of Barind tract of Indo-Bangladesh. J. Int. Soil Water Conserv. Res., 2017, 5(2), 109-121; https://doi.org/10.1016/ j.iswcr.2017.05.003.

21. Wang, W. et al., Dam construction in Lancang-Mekong River Basin could mitigate future flood risk from warming-induced intensified rainfall. J. Geophys. Res. Lett., 2017; https://doi.org/10.1002/ 2017GL075037.

22. Zhang, Y., Xia, J., Liang, T. and Shao Q., Impact of water projects on River flow regimes and water quality in Huai River Basin. J. Water Resour. Manage., 2010, 24, 889-908; https://doi.org/ 10.1007/s11269-009-9477-3.

23. Gassman, P., Reyes, M., Green, C. and Arnold, J. G., The soil and water assessment tool: historical development, applications, and future research directions. $J$. $A S A B E$, 2007, 50(4), 1211-1250.
24. Daggupati, P., Yen, H., White, M. J., Srinivasan, R., Arnold, J. G., Keitzer, C. S. and Sowa, S. P., Impact of model development, calibration, and validation decisions on hydrological simulations in West Lake, Erie Basin. J. Hydrol. Process., 2015, doi:10.1002/ hyp. 10536.

25. Rosenberg, N. J., Epstein, D. J., Wang, D., Vail, L., Srinivasan, R. and Arnold, J. G., Possible impacts of global warming on the hydrology of the Ogallala aquifer region. J Climate Change, 1999, 42(4), 677-692.

26. Srinivasan, M. S., Gerald-Marchant, P., Veith, T. L., Gburek, W. J. and Steenhuis, T. S., Watershed-scale modeling of critical source areas of runoff generation and phosphorus transport. J. Am. Water Resour. Assoc., 2005, 41(2), 361-375.

27. Zhang, X., Srinivasan, R., Zhao, K. and Van Liew, M., Evaluation of global optimization algorithms for parameter calibration of a computationally intensive hydrologic model. J. Hydrol. Process, 2008; doi:10.1002/hyp.7152.

28. Abbaspour, K. C. et al., Modelling hydrology and water quality in the pre-alpine/alpine Thur watershed using SWAT. J. Hydrol., 2007, 333, 413-430.

29. Bekiaris, I. G., Panagopoulos, I. N. and Mimikou, M. A., Application of the SWAT (soil and water assessment tool) model in the Ronnea catchment of Sweden. Global NEST J., 2005, 7(3), 252257.

30. Fohrer, N., Haverkamp, S., Eckhardt, K. and Frede, H. G., Hydrologic response to land use changes on the catchment scale. J. Phys. Chem. Earth (B), 2001, 26(7-8), 577-582.

31. Grizzetti, B., Bouraoui, F., Granlund, K., Rekolainen, S. and Bidoglio, G., Modelling diffuse emission and retention of nutrients in the Vantaanjoki watershed (Finland) using the SWAT model. Ecol. Model., 2003, 169, 25-38; doi:10.1016/S03043800(03)00198-4.

32. Arnold, J. G. et al., SWAT: model use, calibration, and validation. $J$. ASABE, 2012, ISSN 2151-0032.

33. Borah, D. K. and Bera, M., Watershed-scale hydrologic and nonpoint-source pollution models: review of applications. Trans. ASAE, 2004, 47(3), 789-803.

34. Arnold, J. G., Srinivasan, R., Muttiah, R. S. and Williams, J. R., Large-area hydrologic modeling and assessment: Part I. Model development. J. Am. Water Resour. Assoc., 1998, 34(1), 73-89.

ACKNOWLEDGEMENT. We thank the Central Water Commission and India Meteorological Department for providing the hydro-climatic data.

Received 25 January 2020; revised accepted 6 July 2020

doi: $10.18520 / \mathrm{cs} / \mathrm{v} 119 / \mathrm{i} 6 / 1010-1018$ 